\title{
The role of pulmonary ORCC and CLC-2 channels in the response to oxidative stress
}

\author{
Rita Canella ${ }^{1}$ - Mascia Benedusi ${ }^{1} \cdot$ Marta Martini $^{1} \cdot$ Anna Guiotto $^{1} \cdot$ Franco Cervellati $^{1} \cdot{\text { Giuseppe } \text { Valacchi }^{1}{ }^{2,3}}^{2,3}$
}

Accepted: 13 April 2021 / Published online: 7 May 2021

(c) The Author(s) 2021

\begin{abstract}
Background Exposure of human lung epithelial cells to the oxidant pollutant ozone $\left(\mathrm{O}_{3}\right)$ alters cell $\mathrm{Cl}^{-}$currents inducing an outward rectifier effect. Among the various $\mathrm{Cl}^{-}$channels, $\mathrm{ClC}-2$ and ORCC seemed to be involved in this response.

Objectives To identify the channel related to $\mathrm{O}_{3}$ induced current changes.

Results Down regulating the expression of ORCC and $\mathrm{ClC}-2$ genes and analyzing the membrane current show that the enhancement of the current disappeared when ORCC was silenced. The contribution of ORCC and ClC- 2 channels in control and $\mathrm{O}_{3}$ treated cells was obtained by a mathematical approach.

Conclusion We suggest that $\mathrm{O}_{3}$ activates ORCC channels and slightly inhibited ClC-2 channels in the negative voltage range. These findings open the possibility of identifying the biomolecular changes induced by $\mathrm{O}_{3}$ allowing a possible pharmacological intervention towards chloride current due to oxidative stress.
\end{abstract}

Keywords Human lung epithelial cells · Chloride channels · Ozone · Oxidative stress · Patch clamp technique

Rita Canella and Giuseppe Valacchi contributed equally to the work.

Rita Canella

cnr@unife.it

Mascia Benedusi

mascia.benedusi@unife.it

Marta Martini

marta.martini@unife.it

Anna Guiotto

anna.guiotto@student.unife.it

Franco Cervellati

franco.cervellati@unife.it

Giuseppe Valacchi

gvalacc@ncsu.edu

1 Department of Neuroscience and Rehabilitation, University of Ferrara, via L. Borsari, 46, Ferrara, Italy

2 Animal Science Department, Plants for Human Health Institute, NC State University, NC Research Campus 600 Laureate Way, Kannapolis, NC 28081, USA

3 Department of Food and Nutrition, Kyung Hee University, Seoul, South Korea

\section{Introduction}

In Europe, air pollution is considered the second biggest threat to human health after climate change, causing about 500,000 premature deaths affecting mainly children and older people (European Commission 2017; European Environment Agency 2019). Among the different pollutants, Ozone $\left(\mathrm{O}_{3}\right)$ derived from the photochemical smog, has been defined as one of the most toxic outdoor stressors to human health (Mudway and Kelly 2000).

Because of its anatomical structure, location, and function, the lung represents one of the main targets of air pollution (Bargagli 2009) and making this tissue susceptible to damage and to develop pulmonary pathologies (Bowatte 2017; Malhotra et al. 2016; Tomczak 2016; Seaton et al. 1995; Guarnieri and Balmes 2014). Several studies in rodents and humans documented that exposure to a high concentration of $\mathrm{O}_{3}$ can damage cells in the respiratory epithelium leading to bronchial and alveolar conditions (Harkema et al. 1987) with a decrease in lung functions, airway inflammation and hyperactivity, impaired defense mechanisms and a consequent increase in the incidence of respiratory infections (Mudway and Kelly 2000; Ciencewicki et al. 2008; Cross et al. 2002). $\mathrm{O}_{3}$ interaction with the ELF (epithelial lining fluid) leads to the formation of 
bioactive molecules including Reactive Oxygen Species (ROS), and peroxidation products (Laisk et al. 1989; Sarti et al. 2002; Del Corso et al. 1998; Hamilton et al. 1998; Dianzani 1998; Kreuzer et al. 1998; Selley 1998; BoschMorell et al. 1999; Parola et al. 1999; Bhalla 1999).

Cultured type II pneumocytes (A549 cell line (Foster et al. 1998)) are a good model to study the effect of $\mathrm{O}_{3}$ on ion balance between cells and the surrounding environment (Johnson et al. 2006). On the membranes of these cells, there are several types of ion channels and transporters, involved in the homeostatic ions flow between the apical alveolar fluid and the basolateral interstitium (Shabbir et al. 2013). Chloride channels have acquired strong interest from researchers, both because of their activity in epithelial fluid secretion, regulation of cellular volume, proliferation and migration, myelination in the fetus and newborn, ischemia in white brain matter and myocardial cells (He 2017; Zhao et al. 2015) and their involvement in human channelopathies, among which the most known is cystic fibrosis (Verkman and Galietta 2009; Bi et al. 2014).

Since the damaging mechanisms of $\mathrm{O}_{3}$ on ion channels have not yet been fully described, our study focused to evaluate the identification of the lung $\mathrm{Cl}$-channels responsive to $\mathrm{O}_{3}$ (Nilius and Droogmans 2003).

Among all the $\mathrm{Cl}$-channels present in this cell type (Shabbir et al. 2013; Xiang et al. 2013; Brochiero et al. 2004; Chen 2005) our functional studies by means of selective blockers (Verkman and Galietta 2009; Canella et al. 2017, 2018; Sato-Numata et al. 2016), identified the Outward Rectifier Chloride Channels (ORCC) activated by a strong depolarizing event or in conditions of oxidative stress, physiologically analogous to VSORs (outwardly rectifying Cl-volume-sensing channels) and often identified with them (Shimizu et al. 2004) and ClC-2 channels as the channels most likely responsive to $\mathrm{O}_{3}$, although the contribution of each channel needed more investigation.

In this study, we have performed siRNA technique to knock down Anoctamine 6 protein (ANO6), the functional component of ORCC channels (Martins et al. 2011), a member of a family of calcium-activated chloride channels (Ano1-Ano10) (Kunzelmann et al. 2011) indispensable for its operation and of about $65 \%$ for $\mathrm{ClC}-2$ protein. We observed the almost complete block of ORCC and $\mathrm{ClC}-2$ functioning. We then used the trace subtraction technique to get the contribution of each specific type of channel. This technique has been used extensively in electrophysiology from the basic papers of Hodgkin and Huxley (1952) to the present day and it is able to provide cleaner traces than those obtainable with inhibitors, protein knockdown or gene silencing, which cannot always be applied simultaneously on the channels (Martini et al. 2013; Yamanishi et al. 2018). So, with a mathematical approach, we were able to identify with good approximation, the contribution of each channel type to the total current induced by $\mathrm{O}_{3}$ exposure.

\section{Materials and methods}

\section{Cell culture and ozone exposure}

A549 cells (ATCC, Manassas, VA) were cultured in Dulbecco's modified Eagle's medium high glucose (DMEM, Lonza ${ }^{\circledR}$, Milan, Italy) until the ideal confluence was reached as previously described (Valacchi et al. 2011). Cells were exposed to $0.1 \mathrm{ppm}$ of $\mathrm{O}_{3}$ for $30 \mathrm{~min}$ as in the previous studies (Valacchi et al. 2015).

\section{siRNA transfections}

A549 cells were seeded in 6-well plates until 50-60\% confluency and then transfected with 75 pmol negative control\#1 (Scrambled) siRNA (AM4611 Lot\# ASO26WKF, Ambion Austin, TX), or Silencer Select ${ }^{\circledR}$ Pre-designed human Anoctamine 6 siRNA (Cat. Nr. AM16708; ID: 279842, Ambion Austin), or a mixture of CLCN2 siRNA (Cat. Nr. AM 16708A; ID: 113109 and ID: 7419) using Lipofectamine $^{\mathrm{TM}} 2000$ (Invitrogen) and serum-free medium OptiMEM according to the manufacturer's instructions. After $24 \mathrm{~h}$ from the transfection, cell lysates were analyzed by immunoblotting with the related antibody (ANO6 or CLCN2 Polyclonal Antibodies) as described in Western blot section below (Canella et al. 2019).

\section{Cytotoxicity determination}

Cytotoxicity study was performed after siRNA transfections by lactate dehydrogenase (LDH) (EuroClone, Milan, Italy) as previously described (REF PMID: 32504424). Positive control with $100 \%$ toxicity was treated with $2 \%$ (V/V) Triton $\mathrm{X}-100$ in culture media for $30 \mathrm{~min}$ at $37^{\circ} \mathrm{C}$.

\section{Western blot}

Total cell lysates were extracted in RIPA buffer containing protease and phosphatase inhibitor cocktails (Sigma-Aldrich Corp.) and protein concentration was determined by Bradford assay (Biorad Protein assay, Milan, Italy). After protein quantification, $60 \mu \mathrm{g}$ boiled proteins were loaded into $10 \%$ sodium dodecyl sulphate-polycrylamide electrophoresis gels and blotted onto nitrocellulose membranes. The membrane was then blocked and incubated overnight as previously described (Benedusi et al. 2018). 
The primary and secondary antibodies used are: ANO6 Polyclonal Antibody (Cat. Nr. PA5-35240, Thermofisher Scientific) CLCN2 Polyclonal Antibody (Cat. Nr. PA576847, Thermofisher Scientific) diluted 1:1000 (Millipore, Billerica, MA), and the peroxidase-conjugated secondary anti-Rabbit antibody (1:5000). Primary antibodies specificity was assessed by serial dilutions, molecular weight, and orthogonal validation.

\section{Patch-clamp technique}

The procedure was performed as previously reported (Canella et al. 2019). The chemicals were purchased from Sigma-Aldrich. Patch-clamp protocol has a duration of $1400 \mathrm{~ms}$ ranging from +70 to $-110 \mathrm{mV}$ with $20 \mathrm{mV}$ increments from a starting holding potential of $-30 \mathrm{mV}$.

The $\mathrm{O}_{3}$ treated cell samples were examined with patchclamp technique immediately after $30 \mathrm{~min}$ of exposure.

\section{Data analysis and statistical procedures}

Data were analyzed with GraphPad Prism v.6 and reported as mean \pm standard error. Statistical tests performed for control-treated comparisons were Student's $t$ test for means and one-way and two-way ANOVA. $P<0.05$ was the significance level. $P$ values are indicated both in text and graphics.

\section{Results}

\section{Evaluation of ORCC and CIC-2 channels involvement in $\mathrm{O}_{3}$ effect on cell current}

To better elucidate which chloride channel is involved in the action of $\mathrm{O}_{3}$ on chloride ions flow, the proteins ANO6 or ClC-2 were respectively silenced in A549 cells and their protein expression levels were evaluated after $24 \mathrm{~h}$. To overcome the problem of interaction between ORCC and ClC-2 silencing with the functionality of other $\mathrm{Cl}^{-}$channel types, we compared the current-voltage $(I-V)$ curves obtained treating the cells with specific inhibitors of the two channels (DCPIB for ORCC and $\mathrm{CdCl}_{2}$ for ClC-2) obtaining results not significantly different from those obtained by siRNA technique (Insert in Fig. 1; two-way ANOVA test). Since the two current blocking mechanisms are very different, but the results are very similar, we believe that we are reasonably comfortable that siRNA technique does not alter the behavior of other channels.

As shown in Fig. 1, after silencing ANO6 its levels decreased significantly, compared to the controls $(P<0.0001$; one-way ANOVA; post-hoc Bonferroni test). No changes were noticed in the siRNA negative control or Lipofectamine alone. Concerning $\mathrm{ClC}-2$, as shown in
Fig. 1, after silencing its protein levels decreased significantly $(-60 \%$ VS control cells, Lipofectamine, negative control; $P<0.0001$; one-way ANOVA; post-hoc Bonferroni test); also in this case the negative control siRNA or Lipofectamine alone did not show any significant differences. These data indicated that our experiments of siRNA-mediated protein knockdown were efficient and that the knocking down effect achieved by ANO6 or ClC-2-siRNA was specific and effective.

By patch-clamp technique, we analyzed the movement of chloride ions before and after $\mathrm{O}_{3}$ exposure, in control, and when ANO6 or ClC-2 protein were knocked down.

Figure 2 shows the example current traces obtained from a control cell (panel $\mathrm{A})$, an $\mathrm{O}_{3}$-treated cell (panel $\mathrm{B}$ ), an ANO6 silenced cell (panel C), an ANO6 silenced cell treated with $\mathrm{O}_{3}$ (panel D), a ClC-2 silenced cell (panel E), a ClC-2 silenced cell treated with $\mathrm{O}_{3}$ (panel F). The recordings were obtained under voltage-clamp conditions as described in the Materials and Methods section. In panel 2A, the typical time-dependence of the current due to $\mathrm{ClC}-2$ is hidden by the activity of the other channels, especially ORCC, whose contribution is quite important also to negative potentials. The silencing of ANO6 (panels 2C and 2D) makes this phenomenon evident at the more negative potentials.

Patch-clamp protocol was applied to sample of control cells $(n=21)$, cells knocked down for ANO6 $(n=9)$ and cells knocked down for ClC-2 $(n=9)$, obtaining the $I-V$ curves shown in Fig. 3a. Two-way ANOVA test indicated that the control curve as a whole and control knocked down curves were not significantly different $\left(P\left(I_{\text {tot }}\right.\right.$ vs $\left.I_{\text {siANO6 }}\right)=0.12 ; P\left(I_{\text {tot }}\right.$ vs $\left.\left.I_{\text {siClC-2 }}\right)=0.21\right)$; because of the little amplitude of these currents near the resting membrane potential, the contribution of $I_{\text {leak }}$ becomes a more relevant part of the total current, making the comparison of the whole curves not significant. Bonferroni test showed a significant decrease $(P<0.05)$ for the inward part of the siClC-2 curve at $-110 \mathrm{mV}$ and a significant decrease of the siANO6 current at the most negative $(P<0.01$ for $V=-110$ and $-90 \mathrm{mV})$ and most positive potential values $(P<0.01$ for $V=+70$ and $+50 \mathrm{mV}$ ).

The cellular current reversal potentials of both silenced genes $\left(E_{\mathrm{rev}(\mathrm{siANO})}\right)=35.7 \pm 4.1 \mathrm{mV}$; $E_{\text {rev(siClC-2) }}=31.7 \pm 5.7 \mathrm{mV}$ ) are more positive than control cells $\left(E_{\text {rev(tot) }}=17.4 \pm 2.6 \mathrm{mV}\right)$, indicating the lower contribution of the chloride ions to the total current in these conditions $\left(E_{\mathrm{Cl}}=-2.5 \mathrm{mV}\right)$. These results were not surprising for $\mathrm{ClC}-2$, since its contribution to the membrane potential is well known, but it was intriguing for ANO6, which role in control conditions is not yet well clarified. 


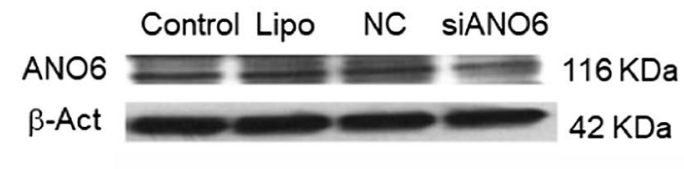

a

WB siANO6, 24h

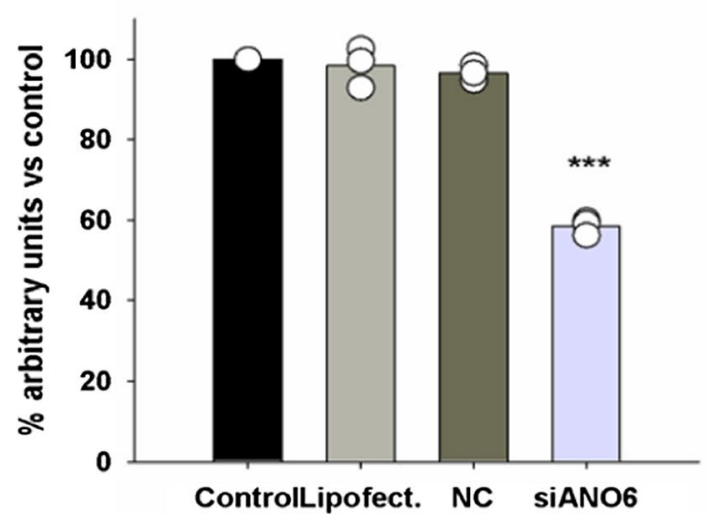

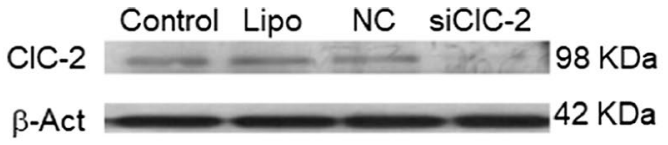

b

WB si CIC-2, 24h

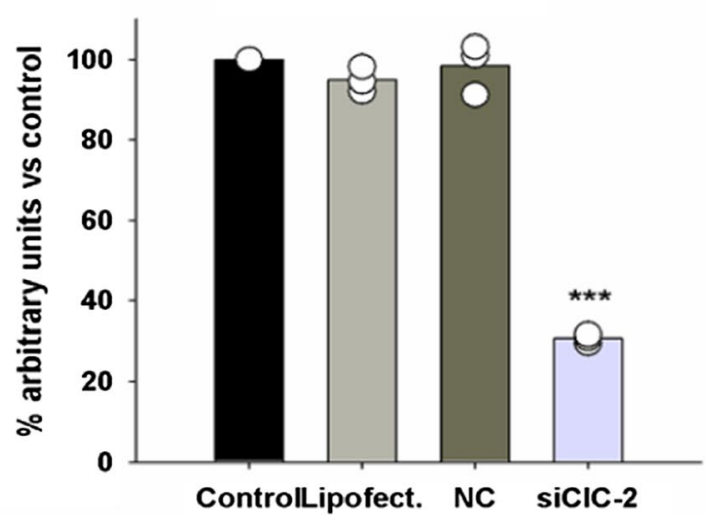

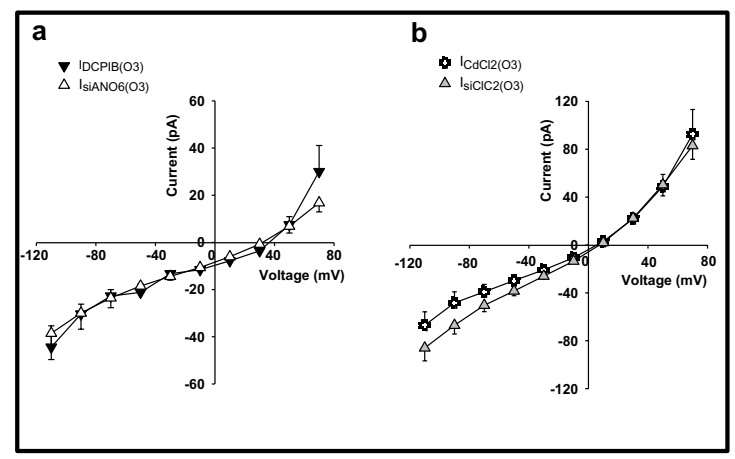

Fig. 1 Silencing of ANO6 and ClC-2: above: A549 cell-line was transfected with siRNA negative control (NC) or siRNA for the silencing of ANO6 (75 pmol) (panel a: siANO6) and ClC-2 (75 pmol) (panel b: ClC-2) for $24 \mathrm{~h}$. The level of ANO6 and ClC-2 proteins were assessed by Western blot analysis with the relative antibody. Representative images are shown with $\beta$-actin as an indicator of loaded proteins. Data are shown as the mean \pm SEM of three independent experiments (single experiment data are shown

\section{Identification of total current components in control conditions}

To dissect the total control current $\left(I_{\text {tot }}\right)$ in its components, we assumed that in our experimental conditions (internal $\mathrm{K}^{+}$ substituted with $\left.\mathrm{Cs}^{+}\right), I_{\text {tot }}$ is due to the contribution of $\mathrm{ClC}-2$ channels $\left(I_{\mathrm{ClC}-2}\right)$, ORCC channels $\left(I_{\mathrm{ORCC}}\right)$ and leak channels $\left(I_{\text {leak }}\right)$ that include the other non-voltage dependent channels present in the cells, as described in the equation (1):

$I_{\mathrm{tot}}=I_{\mathrm{ORCC}}+I_{\mathrm{ClC}-2}+I_{\text {leak }}$

By knocking down ANO6, we consistently reduce $I_{\text {ORCC }}$, so, by the functional response, we can assume that: as white circles). Below: the quantification of the Western blot bands is expressed as arbitrary unit versus control. Statistical test: one-way ANOVA. In the insert: (a) current-voltage relationship of ANO6 silenced and $\mathrm{O}_{3}$ exposed cells $\left(I_{\text {siANO6(O3) }}, n=4\right)$ compared with DCPIB treated and $\mathrm{O}_{3}$ exposed cells $\left(I_{\mathrm{DCPIB}(\mathrm{O} 3)}, n=5\right)$; (b) current-voltage relationship of ClC-2 silenced and $\mathrm{O}_{3}$ exposed cells $\left(I_{\text {siClC-2(O3) }}, n=4\right)$ compared with $\mathrm{CdCl}_{2}$ treated and $\mathrm{O}_{3}$ exposed cells $\left(I_{\mathrm{CdCl} 2(\mathrm{O} 3)}, n=5\right)$

$I_{\text {siANO6 }} \approx I_{\mathrm{ClC}-2}+I_{\text {leak }}$

To estimate the contribution of ORCC channel to the total control current, we can subtract (2) to (1):

$I_{\mathrm{ORCC}} \approx I_{\mathrm{tot}}-I_{\mathrm{siANO6}}$

Since:

$I_{\mathrm{siClC}-2} \approx I_{\mathrm{ORCC}}+I_{\text {leak }}$

we can apply the same formula to calculate $I_{\mathrm{ClC}-2}$ :

$I_{\mathrm{ClC}-2} \approx I_{\mathrm{tot}}-I_{\mathrm{siClC}-2}$

Knowing $I_{\mathrm{ORCC}}$ and $I_{\mathrm{ClC}-2}$ it is possible to obtain $I_{\text {leak }}$ : 
Fig. 2 Representative families of chloride recording currents in control condition: (a), after exposure to $\mathrm{O}_{3}(\mathbf{b})$, after silencing of ANO6 (c), after silencing of ANO6 and $\mathrm{O}_{3}$ exposure (d) after silencing of $\mathrm{ClC}-2$ (e) and after silencing of $\mathrm{ClC}-2$ and $\mathrm{O}_{3}$ exposure (f). Dashed line indicates zero-current level
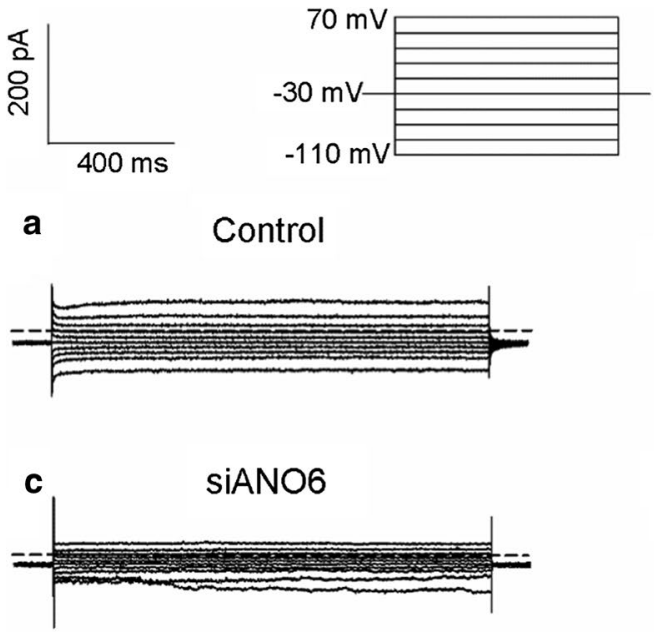

$\operatorname{siClC}-2$

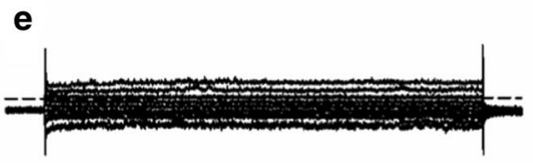

d $\quad$ SIANO6 in Ozone
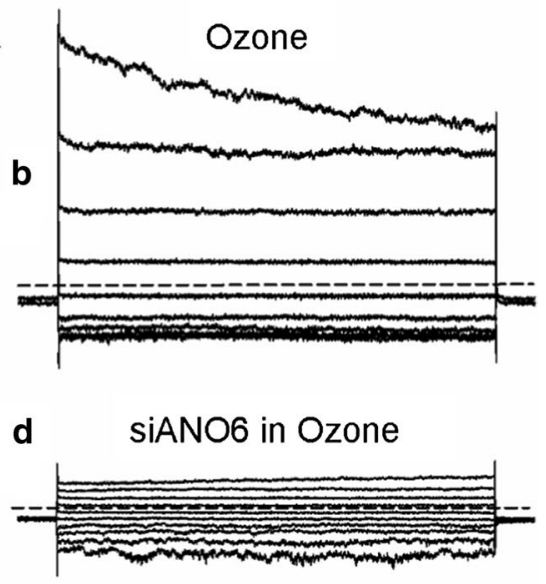

siClC-2 in Ozone

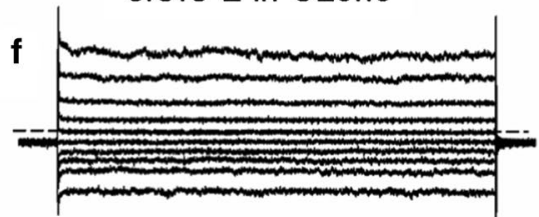

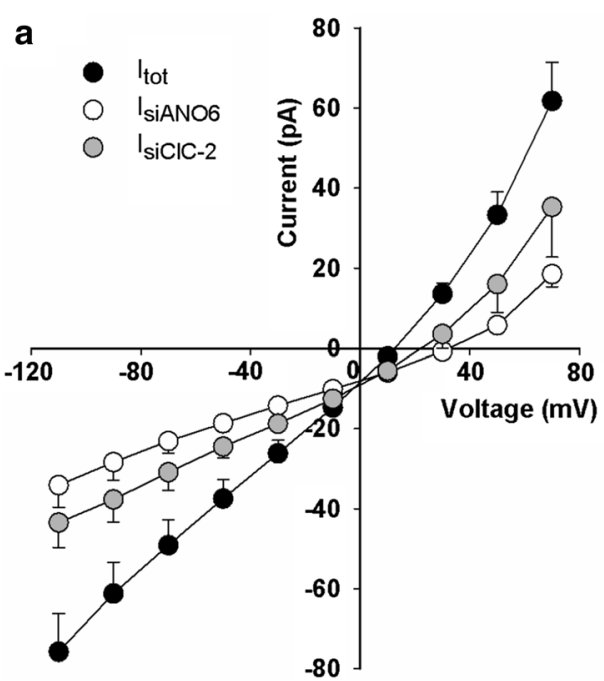

Fig. 3 Current-voltage relationship before and after cell silencing in control conditions: a Current-voltage relationship of control cells $\left(I_{\text {tot }}, n=21\right)$, ANO6 silenced cells $\left(I_{\text {siANO6 }}, n=9\right)$ and ClC-2 silenced cells $\left(I_{\text {siClC-2 }}, n=9\right)$; comparisons between control and silenced cells were performed with two-way ANOVA and were not signifi-

$I_{\text {leak }} \approx I_{\text {tot }}-I_{\mathrm{ClC}-2}-I_{\mathrm{ORCC}}$

Figure 3, panel B shows $I_{\text {tot }}$ and its components.

The reversal potentials of $I_{\mathrm{ClC}-2}$ and $I_{\mathrm{ORCC}}$ $\left(E_{\mathrm{rev}(\mathrm{ClC}-2)}=-2.4 \mathrm{mV} ; E_{\mathrm{rev}(\mathrm{ORCC})}=0 \mathrm{mV}\right)$ are near to

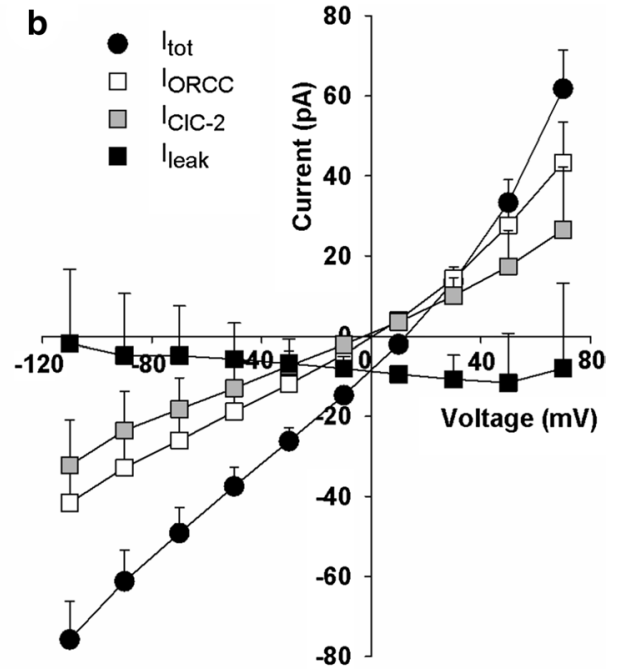

cant $\left(P\left(I_{\text {tot }}\right.\right.$ vs $\left.I_{\text {siANO6 }}\right)=0.12 ; P\left(I_{\text {tot }}\right.$ vs $\left.\left.I_{\text {siClC-2 }}\right)=0.21\right)$ for the overall curves; see Results for details about single points. b Current-voltage relationship of control cells $\left(I_{\text {tot }}, n=21\right)$, ORCC, ClC-2 and leak channels contribution to Itot obtained by mathematical curve subtraction (see Results)

$-2.5 \mathrm{mV}$, the equilibrium potential of chloride ions in our experimental conditions. The ion species responsible for leak current are instead difficult to identify, given the number of channel types that contribute to it. Surely the contribution of cations that move towards the inside of 


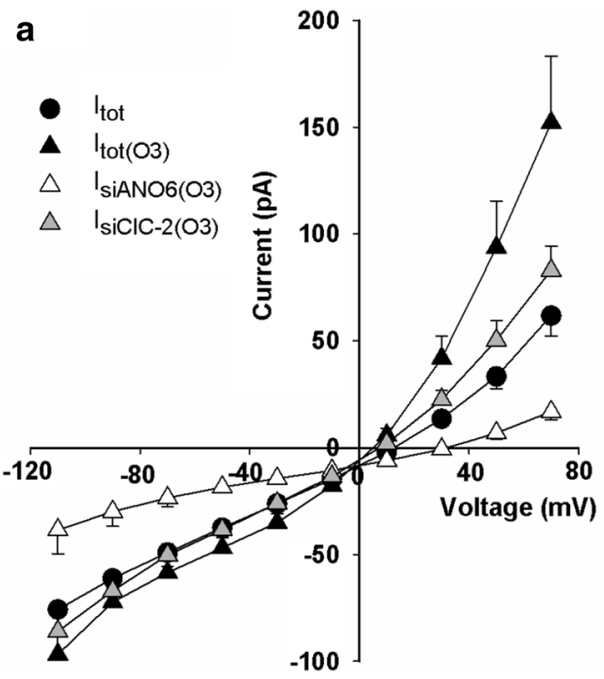

Fig. 4 Current-voltage relationship before and after cell silencing, after $\mathrm{O}_{3}$ treatment: a Current-voltage curves of control cells $\left(I_{\text {tot }}\right.$, $n=21)$, exposed to $\mathrm{O}_{3}\left(I_{\text {tot(O3) }}, n=13\right)$, after silencing of ANO6 and $\mathrm{O}_{3}$ exposure $\left(I_{\text {siANO6(O3) }}, n=4\right)$ and after silencing of $\mathrm{ClC}-2$ and $\mathrm{O}_{3}$ exposure $\left(I_{\mathrm{siClC}-2(\mathrm{O})}, n=4\right)$ cells; the comparisons between the control group and the siANO6 group and the comparison between the $\mathrm{O}_{3}$

the cell is important since the current is inward at all the explored voltage.

\section{Identification of total current components after $\mathrm{O}_{3}$ exposure}

As depicted in Fig. 4a, $\mathrm{O}_{3}$ exposure increases the total current $\left(I_{\text {tot(O3) }}, n=13\right)$ confirming our previous work (Canella et al. 2017). However, when the ANO6 protein is silenced, the effect of $\mathrm{O}_{3}$ decreases and the $I-V$ relationship of the control cells $\left(I_{\text {tot }}\right)$ and the silenced ones $\left(I_{\text {siANO6(O3) }}, n=4\right)$ are not significantly different (two-way ANOVA; $P=0.38$ ). Moreover, the reversal potential of the current, shifts towards more positive values $\left(E_{\text {rev(siANO6(O3)) }}=33.8 \pm 6.7 \mathrm{mV}\right)$ with respect to the reversal potential of $I_{\mathrm{tot}(\mathrm{O} 3)}\left(E_{\mathrm{rev}(\mathrm{tot}(\mathrm{O} 3))}=7.6 \pm 1.7 \mathrm{mV}\right)$.

Treating the $\mathrm{ClC}-2$ silenced cells with $\mathrm{O}_{3}$ resulted in the gray triangles curve $\left(I_{\mathrm{siClC}-2(\mathrm{O} 3)}, n=4\right)$. In these cells, the reaction to $\mathrm{O}_{3}$ exposure is mainly due to ORCC channels and the curve is greater than the control, and was not significantly different from $I_{\mathrm{tot}(\mathrm{O} 3)}$ (two-way ANOVA; $P=0.30$ ). Reversal potential of $I_{\mathrm{siClC}-2(\mathrm{O} 3)}\left(E_{\mathrm{rev}(\mathrm{siClC}-2)}=7.5 \pm 0.5 \mathrm{mV}\right)$ is identical to that of $I_{\text {tot(O3) }}$. From these data, we can extrapolate that ORCC channels significantly respond to $\mathrm{O}_{3}$ exposure. To graphically clarify the contribution of each channel type we operated mathematically.

We can describe the current obtained after $\mathrm{O}_{3}$ exposure as:

$I_{\mathrm{tot}(\mathrm{O} 3)}=I_{\mathrm{ORCC}}+I_{\mathrm{ClC}-2}+I_{\text {leak }}+I_{\mathrm{ORCC}(\mathrm{O} 3)}+I_{\mathrm{ClC}-2(\mathrm{O} 3)}$

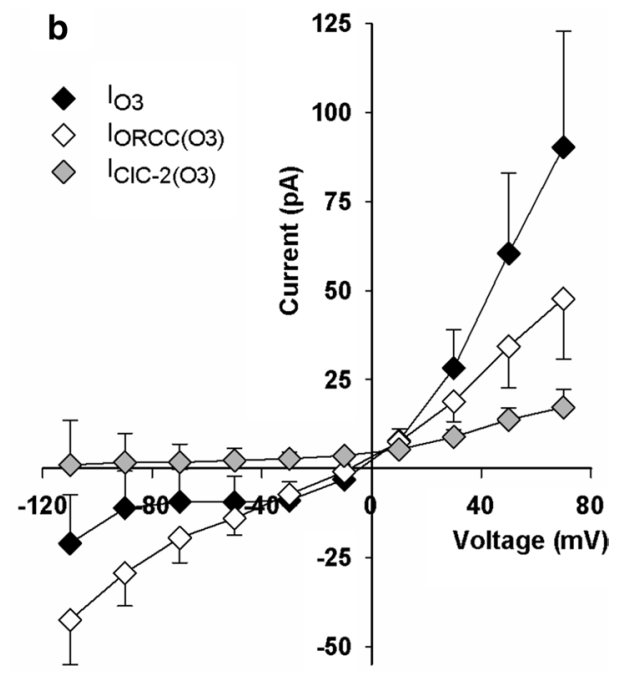

group and the siClC-2 group were not significant (two-way ANOVA: $P\left(I_{\text {tot }}\right.$ vs $\left.I_{\text {siAnO6(O3) }}\right)=0.38 ; P\left(I_{\text {tot(O3) }}\right.$ vs $\left.\left.I_{\text {siClC }-2(\mathrm{O} 3)}\right)=0.30\right)$. b Current-voltage curves mathematically obtained as indicated in Results: current due to $\mathrm{O}_{3}$ action $\left(I_{\mathrm{O} 3}\right)$, part of the $I_{\mathrm{O} 3}$ due to ORCC channels activation $\left(I_{\mathrm{ORCC}}\right)$ and part of the $I_{\mathrm{O} 3}$ due to $\mathrm{ClC}-2$ channels activation $\left(I_{\mathrm{ClC}-2}\right)$

where $I_{\mathrm{ORCC}(\mathrm{O} 3)}$ is the additional part of current induced by $\mathrm{O}_{3}$ on ORCC channels and $I_{\mathrm{CIC}-2(\mathrm{O} 3)}$ is the additional part of current induced by $\mathrm{O}_{3}$ on $\mathrm{ClC}-2$ channels.

$I_{\mathrm{siANO6}(\mathrm{O} 3)} \approx I_{\mathrm{ClC}-2}+I_{\text {leak }}+I_{\mathrm{ClC}-2(\mathrm{O} 3)}$

$I_{\mathrm{siClC}-2(\mathrm{O} 3)} \approx I_{\mathrm{ORCC}}+I_{\mathrm{leak}}+I_{\mathrm{ORCC}(\mathrm{O} 3)}$

Panel B shows the part of total current due to $\mathrm{O}_{3}$ action (black diamonds) obtained subtracting (1) to (4):

$I_{\mathrm{O} 3} \approx I_{\mathrm{ORCC}(\mathrm{O} 3)}+I_{\mathrm{ClC}-2(\mathrm{O} 3)}$

Subtracting (2) to (5) we can obtain an estimate of the contribution to $I_{\mathrm{O} 3}$ of $\mathrm{ClC}-2$ channels. The current is always positive indicating that the effect of $\mathrm{O}_{3}$ on $\mathrm{ClC}-2$ channels is absent or even inhibiting at negative potentials and becomes slightly activating at positive potentials (Fig. 5).

Subtracting (3) to (6) we can obtain an estimate of the contribution to $I_{\mathrm{O} 3}$ of ORCC channels in the same condition.

$I_{\mathrm{CIC}-2(\mathrm{O} 3)} \approx I_{\mathrm{SiANO6(O3)}}-I_{\mathrm{siANO} 6}$

$I_{\mathrm{ORCC}(\mathrm{O} 3)} \approx I_{\mathrm{siClC} \mathrm{-} \mathrm{(O3)}}-I_{\mathrm{SiClC} \mathrm{-}}$

\section{Effect of $\mathrm{O}_{3}$ on ORCC and CIC-2 channels}

To visualize the effect of $\mathrm{O}_{3}$ on the current passing through the ORCC and $\mathrm{ClC}-2$ channels, we compared the total ORCC current after $\mathrm{O}_{3}$ treatment $\left(I_{\mathrm{ORCC}}+I_{\mathrm{ORCC}(\mathrm{O} 3)}\right)$ with 

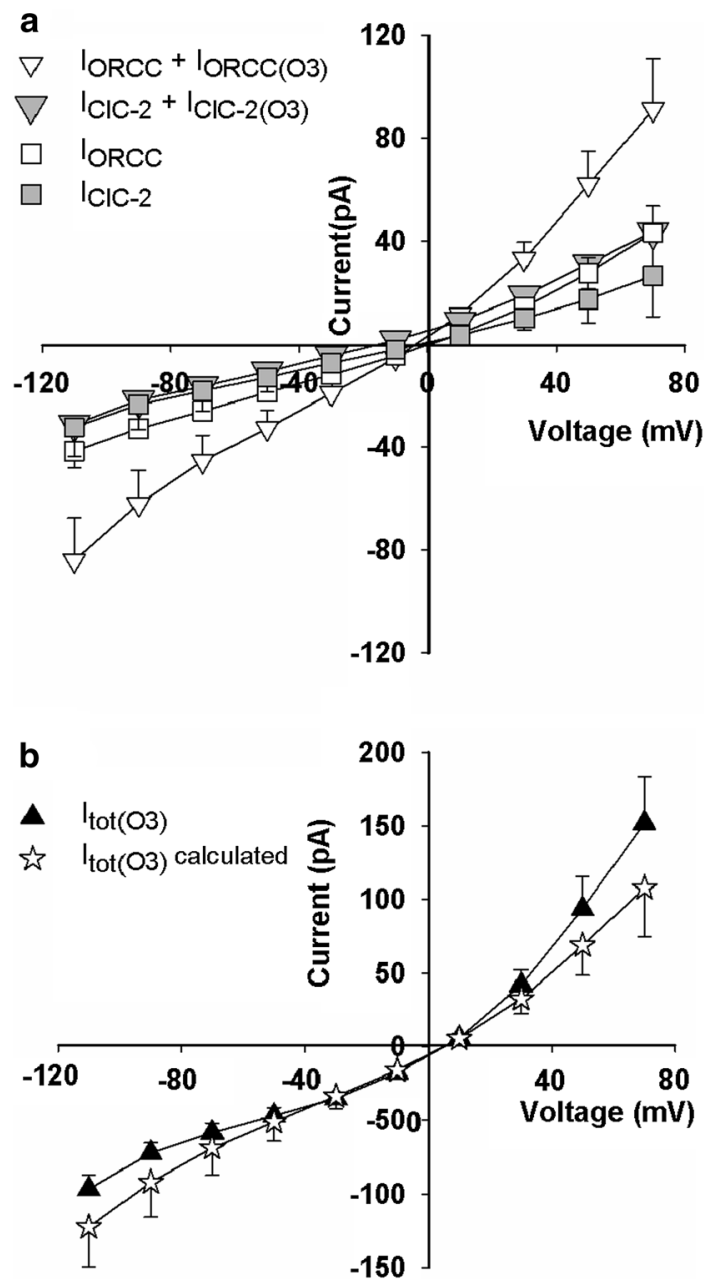

Fig. 5 Contribution of ORCC and ClC-2 channels to the membrane current after $\mathrm{O}_{3}$ treatment: a current-voltage curves mathematically obtained as indicated in Results: contribution to $I_{\text {tot(O3) }}$ due to ORCC channels $\left(I_{\mathrm{ORCC}}+I_{\mathrm{ORCC}(\mathrm{O} 3)}\right)$ and to $\mathrm{ClC}-2$ channels $\left(I_{\mathrm{ClC}-2}+I_{\mathrm{ClC}-2(\mathrm{O} 3)}\right)$ compared to the corresponding basal current $\left(I_{\mathrm{ORCC}}\right.$ and $\left.I_{\mathrm{ClC}-2}\right)$. See Results for statistical analysis. b Current-voltage curves of cells exposed to $\mathrm{O}_{3}\left(I_{\text {tot(O3) }}, n=13\right)$ and mathematical reconstruction of $I_{\text {tot(O3) }}$. The comparison between the two curves was not significant (two-way ANOVA; $P=0.47$ )

the ORCC current in the control condition. The same comparison has been done for $\mathrm{ClC}-2$ current. The results are shown in Fig. 5, panel A.

$\mathrm{O}_{3}$ induces a significant increase both of inward (two-way ANOVA; $P<0.001$ ) and outward current (two-way ANOVA; $P<0.001)$ due to ORCC channel, while ClC-2 channels activity is slightly enhanced only for the outward part of the curve (two-way ANOVA; not significant; $P=0.11$ ).
Adding the components of the total current calculated under control conditions (Eqs. 2a, 3a and 3b), with the contribution given to the current by the ORCC and $\mathrm{ClC}-2$ channels when the cells are treated with $\mathrm{O}_{3}$ (Eqs. 7a and $7 \mathrm{~b})$, the $I_{\text {tot(O3) }}$ has been reconstructed.

The comparison between the experimental curve and the reconstructed one is depicted in Fig. 5b.

Two-way ANOVA test between observed data and calculated ones is not significant $(P=0.47)$, supporting our reconstruction procedure.

\section{Discussion}

Our previous work demonstrated that, in A549 cells, exposure to $\mathrm{O}_{3}$ causes a considerable increase of the total membrane current, mainly in its outward component. The functional experiments implemented to identify the responsible channels for this alteration by means of ORCC and $\mathrm{ClC}-2$ channels inhibitors did not unambiguously identify the $\mathrm{O}_{3}$ target. In this study, we discern the contribution of $\mathrm{ClC}-2$ and ORCC channels to the current induced upon $\mathrm{O}_{3}$ exposure, by siRNA technique and a mathematical approach applied to patch-clamp traces.

The gene encoding for ANO6, a functional part of ORCC (Martins et al. 2011), was silenced and the currents were analyzed before and after $\mathrm{O}_{3}$ exposure (Fig. 3a and $4 a)$.

Surprisingly, patch-clamp recordings on knocked down cells in the control condition, showed that an important part of the chloride current is due to ORCC channels. This finding indicated that the ORCC channels are not only activated by depolarizing potentials or in presence of oxidative stress, as reported in the literature (Toczyłowska-Mamińska and Dołowy 2012; Wanitchakool et al. 2016), but they contribute to the physiological membrane potential. This observation is of particular interest since the role of this channel in control conditions has not been yet analyzed. The overall $I-V$ relationship of silenced cells is non-significantly different from the control, but the current values are lower than those of the control at all considered potentials. In particular, those evoked at the most positive $(+70$ and $+50 \mathrm{mV} ; P<0.001$; $P<0.05)$ and negative $(-110$ and $-90 \mathrm{mV} ; P<0.001$; $P<0.01)$ potentials are significantly different from the control (two-way ANOVA, Bonferroni test).

When we silenced ClC-2 gene, the comparison between the obtained $I-V$ curve and the control one, shows a significant decrease of the current at very negative potentials ( $-110 \mathrm{mV} ; P<0.05$; two-way ANOVA, Bonferroni test), indicating the important contribution of this channel at the membrane resting potential and its inward rectifier behavior already reported in literature (Cuppoletti et al. 2000). 
The reversal potential of both currents after silencing, shifts towards very positive potentials, far from the equilibrium potential for chloride ions in our model $\left(E_{\mathrm{Cl}}=-2.5 \mathrm{mV}\right)$. Since in our experiments, only chloride ions have an equilibrium potential round $0 \mathrm{mV}$, this result confirms the closing of chloride conductance in both cases.

With the mathematical approach, we attempt to identify the contribution to the total control current of ORCC and $\mathrm{ClC}-2$ channels. Our experiments show that from the functional point of view, the silencing approach almost completely eliminates the current carried by the type of targeted channels. In any case, the subtraction of traces makes the presence of any residual current irrelevant.

The reversal potential of both calculated currents is very close to $E_{\mathrm{Cl}}$ indicating the ability of the mathematical approach to isolate the control current components. On the other side, leak current is a compound inward current that does not revert in the analyzed voltage range, indicating the cations prevailing role for leakage current.

When the silenced cells are exposed to $\mathrm{O}_{3}$, the current of siANO6 cells does not show any enhancement and its reversal potential becomes very positive $\left(E_{\text {rev(siAnO6(O3)) }}=\right.$ $33.8 \pm 6.7 \mathrm{mV}$ ), while the current of siClC-2 cells results not statistically different from the current of $\mathrm{O}_{3}$ treated cells and the reversal potential is similar to $E_{\text {rev(tot(O3)) }}$ (see Results). This finding indicates that the current induced by $\mathrm{O}_{3}$ exposure is mostly due to ORCC channels activation.

Dissecting the contribution of each channel type to the $\mathrm{O}_{3}$ effect, we can also show that $\mathrm{O}_{3}$ slightly inhibits $\mathrm{ClC}-2$ inward current: the calculated values of ClC-2 current at the negative voltage values, were positive as if an outward current was added to the inward original one. In fact, subtracting an inward current by closing the corresponding channels, is mathematically equivalent to adding an outward current. Unfortunately, the effect of $\mathrm{O}_{3}$ on the negative current due to $\mathrm{ClC}-2$ did not reach a statistically significant value.

Figure 5a shows the ORCC current after $\mathrm{O}_{3}$ treatment as the summation of the basal activity of ORCC ( $\left.I_{\text {ORCC }}\right)$ and the activity due to $\mathrm{O}_{3}$ action $\left(I_{\mathrm{ORCC}(\mathrm{O} 3)}\right)$ and compares it with the basal ORCC current $\left(I_{\mathrm{ORCC}}\right)$ alone. The comparison indicates an increase of both the outward and the inward components of the current after $\mathrm{O}_{3}$ exposure. This finding is intriguing because ORCC channels are considered outward rectifier (Mall and Galietta 2015), nevertheless, our results indicated that the current is almost linear and that after $\mathrm{O}_{3}$ exposure, the outward effect in our cells is mainly due to the interplay of the three main current present in the cells: $I_{\mathrm{ORCC}}, I_{\mathrm{ClC}-2}$ and $I_{\text {leak }}$. These data will induce us to investigate, in our future studies, whether $\mathrm{O}_{3}$ influences, in addition to the number of open channels, also their voltage-dependence.
We have made the same calculation for $\mathrm{ClC}-2$ current. In this case, the comparison between the $\mathrm{ClC}-2$ current after $\mathrm{O}_{3}$ exposure $\left(I_{\mathrm{ClC}-2}+I_{\mathrm{ClC}-2(\mathrm{O} 3)}\right)$ and the basal $I_{\mathrm{ClC}-2}$, clarifies what observed (Fig. 4b): the inward part of the current is very marginally influenced by the action of $\mathrm{O}_{3}$, while the outward part has a slight increase. This effect is not sufficient to compensate for the loss of efficacy of ORCC channels in $\mathrm{O}_{3}$-treated and ANO6 silenced cells and to make the total current significantly different from control.

Finally, to verify the correctness of our mathematical deductions, we reconstructed according to the procedure indicated in the results, the total current expressed by the cells when they are treated with $\mathrm{O}_{3}\left(I_{\text {tot(O3) }}\right.$ calculated $)$ and we compared it with the experimental curve $I_{\text {tot(O3) }}$.

These results show that our approach is able to identify the contribution of the different channel types to the total experimental current in an accurate and precise way.

Given the importance of the $\mathrm{Cl}^{-}$current in pulmonary alveolar cells, it becomes fundamental to know the contribution of the different types of channels to the membrane current in physiological and oxidative stress conditions. In fact, the unbalance of the chloride ions distribution leads to diseases such as cystic fibrosis (Mall and Galietta 2015) where the CFTR channel/transporter is defective. Therefore, becomes very important to find drugs able to rebalance the distribution of chloride ions, acting on the non-defective chloride channels.

Author contributions RC: conceptualization, methodology, validation, investigation, writing-reviewing and editing; MB: conceptualization, methodology, validation, investigation, and writing-original draft; MM: formal analysis, investigation and data curation; AG: investigation and resources; FC: resources and software; GV: conceptualization; writing-reviewing, editing and supervision and project administration.

Funding Open access funding provided by Università degli Studi di Ferrara within the CRUI-CARE Agreement. Università degli Studi di Ferrara (FAR 2018), Prof. Giuseppe Valacchi.

\section{Declarations}

Conflict of interest Rita Canella, Mascia Benedusi, Marta Martini, Anna Guiotto, Franco Cervellati, Giuseppe Valacchi confirm that they have no conflicts of interest to disclose.

Ethical approval This article does not contain any studies with human participants or animals performed by any of the authors.

Open Access This article is licensed under a Creative Commons Attribution 4.0 International License, which permits use, sharing, adaptation, distribution and reproduction in any medium or format, as long as you give appropriate credit to the original author(s) and the source, provide a link to the Creative Commons licence, and indicate if changes were made. The images or other third party material in this article are included in the article's Creative Commons licence, unless indicated otherwise in a credit line to the material. If material is not included in 
the article's Creative Commons licence and your intended use is not permitted by statutory regulation or exceeds the permitted use, you will need to obtain permission directly from the copyright holder. To view a copy of this licence, visit http://creativecommons.org/licenses/by/4.0/.

\section{References}

Bargagli E et al (2009) Oxidative stress in pathogenesis of diffuse lung diseases: a review. Respir Med 103:1245-1256

Benedusi M, Frigato E, Beltramello M, Bertolucci C, Valacchi G (2018) Circadian clock as possible protective mechanism to pollution induced keratinocytes damage. Mech Ageing Dev 172:13-20

Bhalla DK (1999) Ozone-induced lung inflammation and mucosal barrier disruption: toxicology, mechanisms, and implications. J Toxicol Environ Health B Crit Rev 2:31-86

Bi MM et al (2014) Chloride channelopathies of ClC-2. Int J Mol Sci 15:218-249

Bosch-Morell F, Flohé L, Marín N, Romero FJ (1999) 4-hydroxynonenal inhibits glutathione peroxidase: protection by glutathione. Free Rad Biol Med 26:1383-1387

Bowatte G et al (2017) Traffic-related air pollution exposure is associated with allergic sensitization, asthma, and poor lung function in middle age. J Allergy Clin Immunol 139:122-129.e1

Brochiero E, Dagenais A, Privé A, Berthiaume Y, Grygorczyk R (2004) Evidence of a functional CFTR Cl-channel in adult alveolar epithelial cells. Am J Physiol Lung Cell Mol Physiol 287:L382-L392

Canella R et al (2017) Modulation of chloride currents in human lung epithelial cells exposed to exogenous oxidative stress. J Cell Physiol 232(7):1817-1825

Canella $\mathrm{R}$ et al (2018) Role of Nrf2 in preventing oxidative stress induced chloride current alteration in human lung cells. Journal of Cell Physiology 233:6018-6027

Canella $R$ et al (2019) Involvement of the TREK-1 channel in human alveolar cell membrane potential and its regulation by inhibitors of the chloride current. J Cell Physiol 234(10):17704-17713. https:// doi.org/10.1002/jcp. 28396

Chen T-Y (2005) Structure and function of CLC channels. Annu Rev Physiol 67:809-839

Ciencewicki J, Trivedi S, Kleeberger SR (2008) Oxidants and the pathogenesis of lung disease. J Allergy Clin Immunol 122:456-468

Cross CE et al (2002) Environmental oxidant pollutant effects on biologic systems: a focus on micronutrient antioxidant-oxidant interactions. Am J Respir Crit Care Med 166:S44-50

Cuppoletti J, Tewari KP, Sherry AM, Malinowska DH (2000) Activation of human $\mathrm{ClC}-2 \mathrm{Cl}-$ channels: implications for cystic fibrosis. Clin Exp Pharmacol Physiol 27:896-900

Del Corso A et al (1998) Site-specific inactivation of aldose reductase by 4-hydroxynonenal. Arch Biochem Biophys 350:245-248

Dianzani MU (1998) 4-Hydoxynonenal and cell signaling. Free Rad Res 28:553-560

European Commission (2017) Special Eurobarometer 468: Attitudes of European citizens towards the environment. http://data.europa. eu/euodp/en/data/dataset/S2156_88_1_468_ENG. Accessed 20 Jun 2019

European Environment Agency, Report (2019)

Foster KA, Oster CG, Mayer MM, Avery ML, Audus KL (1998) Characterization of the A549 cell line as a type ii pulmonary epithelial cell model for drug metabolism. Exp Cell Res 243:359-366

Guarnieri M, Balmes JR (2014) Outdoor air pollution and asthma. Lancet 383:1581-1592
Hamilton RF Jr, Li L, Eschenbacher WL, Szweda L, Holian A (1998) Potential involvement of 4-hydroxynonenal in the response of human lung cells to ozone. Am J Physiol 274:L8-L16

Harkema JR et al (1987) Response of the macaque nasal epithelium to ambient levels of ozone. A morphologic and morphometric study of the transitional and respiratory epithelium. Am J Pathol 128:29

$\mathrm{He} \mathrm{F}$ et al (2017) Activated ClC-2 Inhibits p-Akt to repress myelination in GDM newborn rats. Int J Biol Sci. 13(2):179-188. https://doi. org/10.7150/ijbs.17716 (eCollection 2017)

Hodgkin AL, Huxley AF (1952) Currents carried by sodium and potassium ions through the membrane of the giant axon of Loligo. J Physiol 116:449-472

Johnson MD et al (2006) Functional ion channels in pulmonary alveolar type I cells support a role for type I cells in lung ion transport. Proc Natl Acad Sci USA 13:4964-4969

Kreuzer T, Grube R, Wutte A, Zarkovic N, Schaur RJ (1998) 4-hydroxinonenal modifies the effects of serum growth factors on the expression of the c-fos-proto-oncogene and the proliferation of HeLa carcinoma cells. Free Rad Biol Med 25:42-49

Kunzelmann K et al (2011) Anoctamins. Pflügers Arch Eur J Physiol 462:195-208

Laisk A, Kull O, Moldau H (1989) Ozone concentration in leaf intercellular air spaces is close to zero. Plant Physiol 90:1163-1167

Malhotra J, Malvezzi M, Negri E, La Vecchia C, Boffetta P (2016) Risk factors for lung cancer worldwide. Eur Respir J 48:889-902

Mall MA, Galietta LJ (2015) Targeting ion channels in cystic fibrosis. J Cyst Fibros 14:561-570

Martini M, Canella R, Fesce R, Rossi ML (2013) The amplitude and inactivation properties of the delayed potassium currents are regulated by protein kinase activity in hair cells of the frog semicircular canals. PLoS ONE 8(7):e67784. https://doi.org/10.1371/journ al.pone. 0067784

Martins JR et al (2011) Anoctamin 6 is an essential component of the outwardly rectifying chloride channel. Proc Natl Acad Sci USA 108:18168-18172

Mudway IS, Kelly FJ (2000) Ozone and the lung a sensitive issue. Mol Aspects Med 21:1-48

Nilius B, Droogmans G (2003) Amazing chloride channels: an overview. Acta Physiol Scand 177:119-147

Parola M, Bellomo G, Robino G, Barrera G, Dianzani MU (1999) 4-Hydroxinonenal as a biological signal: molecular basis and pathophysiological implication. Antiox Redox Signal 1:255-284

Sarti P, Avigliano L, Görlach A, Brüne B (2002) Superoxide and nitric oxide-participation in cell communication. Cell Death Differ 9:1160-1162

Sato-Numata K, Numata T, Inoue R, Okada Y (2016) Distinct pharmacological and molecular properties of the acid-sensitive outwardly rectifying (ASOR) anion channel from those of the volume-sensitive outwardly rectifying (VSOR) anion channel. Pflügers Arch Eur J Physiol 468:795-803

Seaton A, MacNee W, Donaldson K, Godden D (1995) Particulate air pollution and acute health effects. Lancet 345:176-178

Selley ML (1998) (E)-4-hydroxy-2-nonenal may be involved in the pathogenesis of Parkinson's disease. Free Rad Biol Med 25:169-174

Shabbir W et al (2013) Mechanism of action of novel lung edema therapeutic AP301 by activation of the epithelial sodium channel. Mol Pharmacol 84:899-910

Shimizu T, Numata T, Okada Y (2004) A role of reactive oxygen species in apoptotic activation of volume-sensitive $\mathrm{Cl}(-)$ channel. Proc Natl Acad Sci USA 101:6770-6773

Toczyłowska-Mamińska R, Dołowy K (2012) Ion transporting proteins of human bronchial epithelium. J Cell Biochem 113:426-432

Tomczak A et al (2016) Long-term exposure to fine particulate matter air pollution and the risk of lung cancer among participants 
of the Canadian National Breast Screening Study. Int J Cancer 139:1958-1966

Valacchi G et al (2011) Cigarette smoke exposure causes changes in scavenger receptor B1 level and distribution in lung cells. Int J Biochem Cell Biol 43(7):1065-1070. https://doi.org/10.1016/j. biocel.2009.05.014

Valacchi G et al (2015) Vitamin C compound mixtures prevent ozoneinduced oxidative damage in human keratinocytes as initial assessment of pollution protection. PLoS ONE 10:e0131097

Verkman AS, Galietta LJV (2009) Chloride channels as drug targets. Nat Rev Drug Discov 8:153-171

Wanitchakool P et al (2016) Cl- channels in apoptosis. Eur Biophys J 45:599

Xiang YY et al (2013) Isoflurane regulates atypical type-A $\gamma$-aminobutyric acid receptors in alveolar type II epithelial cells. Anesthesiology 118:1013-1015
Yamanishi T, Koizumi H, Navarro MA, Milescu LS, Smith JC (2018) Kinetic properties of persistent $\mathrm{Na}+$ current orchestrate oscillatory bursting in respiratory neurons. J Gen Physiol 150(11):15231540. https://doi.org/10.1085/jgp.201812100

Zhao B et al (2015) 4,4'-Diisothiocyanostilbene-2,2'-disulfonic acid (DIDS) ameliorates ischemia-hypoxia-induced white matter damage in neonatal rats through inhibition of the voltage-gated chloride channel ClC-2. Int J Mol Sci 6(5):10457-10469. https://doi. org/10.3390/ijms160510457

Publisher's Note Springer Nature remains neutral with regard to jurisdictional claims in published maps and institutional affiliations. 